\title{
Neue IT-Welt: Wunderwaffe der Controller oder deren Totengräber?
}

\section{Liebe Leserinnen und Leser,}

die Entwicklung der Controller von Erbsenzählern zu Business Partnern ist untrennbar mit der Entwicklung ihrer IT-Werkzeuge verbunden. Erst die Einführung moderner ERP-Systeme verschaffte den Controllern einen komfortablen und ressourcenarmen Zugriff auf die von ihnen benötigten Informationen. Befreit von lästigen Datenbereitstellungsaufgaben war genügend Zeit, um die Geschichten hinter den Zahlen zu lernen und in die Rolle eines umfassenden ökonomischen Beraters hineinzuwachsen. Die freigemachte Kapazität der Controller wurde damals noch nicht zur Reduktion der Controller-Stellen verwendet. Sie konnte vielmehr nutzbringend in neue, anspruchsvolle Aufgaben investiert werden.

Heute sind Controller mit einer erneuten grundlegenden Veränderung in der IT konfrontiert, die sich mit den Schlagworten Mobilität, Self Service und Echtzeitverarbeitung beschreiben lässt. Benötigte Informationen liegen in höchster Aktualität zur unmittelbaren Nutzung an jedem beliebigen Platz in der Welt bereit. Controller können schneller und komfortabler Auswertungen vornehmen. Controller sparen erneut Zeit ein und haben wieder mehr Kapazität frei, um die Manager noch anspruchsvoller zu unterstützen. Ist damit eine Fortsetzung der überaus erfolgreichen Entwicklung der Controller in der letzten Dekade vorprogrammiert?

Man muss schon ein ausgeprägter Optimist sein, um dies zu prognostizieren. Auf der einen Seite macht der Effizienzdruck nicht mehr vor dem Controller-Bereich halt. Freigesetzte Kapazität wird gerne umgehend durch Stellenstreichung einkassiert. Auf der anderen Seite verschaffen die neuen IT-Möglichkeiten nicht nur Controllern Vorteile. Vielmehr versetzen sie Manager erstmals in die Lage, ihren Informationsbedarf auf sehr einfache und komfortable Weise selbst zu decken. Es gibt schon Unternehmen, in denen die Controller nur noch ein Baukastensystem möglicher sinnvoller Auswertungsmöglichkeiten - Apps vergleichbar - bereithalten, mittels derer die Manager quasi ihr eigenes Reporting gestalten. Damit sind sie täglich immer auf dem neuesten Stand, und das genau mit den Informationen, die sie sich

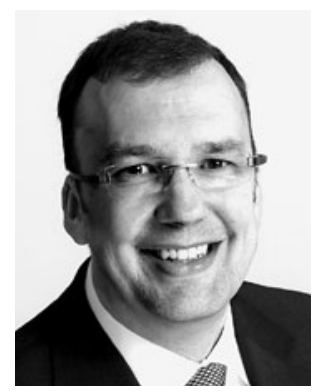

Utz Schäffer

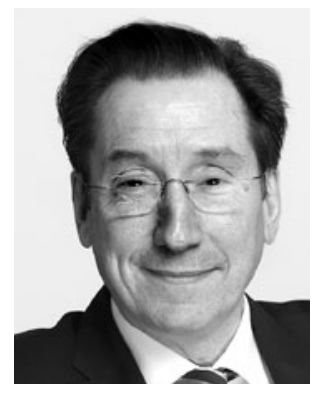

Jürgen Weber selbst für die Steuerung ihrer Einheiten ausgesucht haben. Self Controlling wird von einer lange bekannten Idee zur Realität.

Das Berichtswesen bindet Controller - wie wir aus dem WHU-Controllerpanel wissen - heute noch mit mehr als einem Fünftel ihrer Kapazität. Deutliche Veränderungen auf diesem Feld haben das Potenzial, den Controller-Bereich insgesamt zu verändern. Die mit der IT-Entwicklung verbundene Standardisierung und Automatisierung von Controlling-Prozessen kommt hinzu. Controller dürfen sich also nicht auf dem erzielten Erfolg, Business Partner geworden zu sein, ausruhen. Sie sollten ganz nüchtern die Konsequenzen der IT-Entwicklung überdenken und sie in ihre eigenen Planungen einbauen. Dies setzt entsprechende Kenntnisse voraus. Dazu will dieses Heft einen Beitrag leisten.

Viel Spaß bei der Lektüre wünschen Ihnen
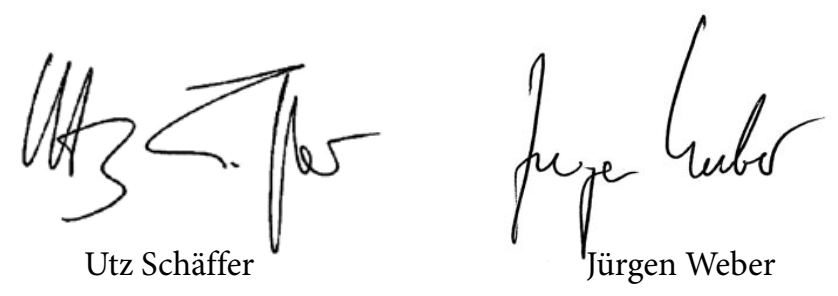